\title{
Prerequisite Evaluation of Engineering Skills
}

\author{
Gérard J. Poitras ${ }^{1}$ \\ Eric G. Poitras ${ }^{2}$ \\ 1. Professor, Faculté d'ingénierie, Université de Moncton, NB, CA \\ 2. Assistant Professor, Department of Educational Psychology, University of Utah, UT, US
}

\begin{abstract}
Preliminary findings obtained from a threeyear study are presented where different cohorts of undergraduate civil engineering students are followed for three consecutive years while completing the Civil Engineering program at the Université de Moncton. This study outlines how a set of problem instances were developed, wherein a student performs a series of steps to formulate a solution. These steps are mapped to one or more skills, also known as procedural knowledge components, which are essential for students to have mastered from one or more previous courses in order to successfully complete the course in question. Over a hundred students from the second, third, or fourth year performed a series of problem-solving tasks that assess a common set of skills at the beginning of their respected courses. The findings obtained from the first year of this study show that students vary in their abilities to correctly solve instances of a problem on their first attempt. This suggests that there is a pressing need for assessment tools that target progressions for specific courses using the range of standards outlined by the Canadian Engineering Accreditation Board as progress indicators while providing individualized instructional modules developed on the basis of research-based understanding of how these skills develop over time for all students.
\end{abstract}

Keywords: prerequisites, engineering, engineering education, skill assessment, Canadian engineering accreditation board.

\section{INTRODUCTION}

Engineering programs contain a list of mandatory courses and electives that identify prerequisites for more advanced courses. One of the most important assumption for listing prerequisites to a course is that understanding complex engineering concepts requires prior knowledge of a particular domain and a set of necessary skills that are interdependent. Despite the importance for program administrators to organize the curriculum to focus on core skill sets that follow one another as students learn, there remains a paucity of evidence on how such skills develop over time.
A broader perspective has been adopted by [1], who coined the term learning progressions to track student progress along varying levels of achievement and establish individual trajectories towards competency informed by empirical research. From this perspective, there is an emphasis on the distinction between hypothetical and empirical learning progressions, while a valid progression implies that the underlying model of skill acquisition holds true across courses and for different students [2]. However, it is to be expected that prerequisite skills may not necessarily be mastered by the learner even though he or she has successfully completed a course. The barriers to personalizing instruction include what skills to assess, when to do so, and when to administer assessments given the particular constraints and expectations inherent to a program. There is a need to address these issues through the diagnosis of students' level of performance based on a learning progression, in particular, while students move from one course to another. The rationale is to enable instructors to tailor the curriculum to the specific needs of different students.

This study outlines preliminary findings obtained from a longitudinal examination of skill acquisition in the engineering domain. In particular, we describe the steps taken to develop and validate diagnostic assessment tools that specifically target structural engineering knowledge and skills. Diagnostic assessment instruments are argued to provide professors with the necessary tools to create individualize instruction that target skill progressions across specific courses to recommend remedial materials and activities. The implications of the proposed method is discussed in the context of the range of standards outlined by the Canadian Engineering Accreditation Board.

\section{METHODOLOGY}

\subsection{Civil engineering curriculum}

As shown in Table 1, we chose a sample of courses for the purposes of analysis of prerequisite skills in relation to structural engineering. Each course is identified along with a prerequisite (e.g., Basic chemistry is a prerequisite to engineering materials). Hypothetical problem-solving 
skills that may mediate task performance are listed for each course (e.g., Normal stress, stress concentration, and so on). The underlying assumption is that each skill has been mastered by the students prior to enrolling in each course given that they successfully completed the prerequisite course.

Table 1: Structural engineering courses

\begin{tabular}{|c|c|c|}
\hline Course & Prerequisites & Related skills \\
\hline $\begin{array}{l}\text { Engineering } \\
\text { materials }\end{array}$ & Basic chemistry & $\begin{array}{l}\text { Normal stress, stress } \\
\text { concentration, stress } \\
\text { strain diagram, etc. }\end{array}$ \\
\hline Statics & Math & $\begin{array}{l}\text { Centre of gravity, } \\
\text { moment of inertia, } \\
\text { shear and bending } \\
\text { moment diagrams, } \\
\text { etc. }\end{array}$ \\
\hline Strength of materials & $\begin{array}{l}\text { Engineering } \\
\text { materials \& Statics }\end{array}$ & $\begin{array}{l}\text { Normal stress, stress } \\
\text { concentration, stress } \\
\text { strain diagram, shear } \\
\text { stress, bending } \\
\text { stress, buckling } \\
\text { stress, stress in } \\
\text { composite material, } \\
\text { etc. }\end{array}$ \\
\hline Structural analysis & Statics & $\begin{array}{l}\text { Limit state design, } \\
\text { loads, shear and } \\
\text { bending moment } \\
\text { diagrams, beam } \\
\text { deformation, etc. }\end{array}$ \\
\hline $\begin{array}{l}\text { Analysis of statically } \\
\text { indeterminate } \\
\text { structures }\end{array}$ & Structural concepts & $\begin{array}{lr}\text { Approximate } & \\
\text { analysis, force } & \\
\text { methods, matrix } \\
\text { analysis, computer } \\
\text { analysis, etc. }\end{array}$ \\
\hline Steel design & $\begin{array}{l}\text { Structural concepts } \\
\& \text { Strength of } \\
\text { materials }\end{array}$ & $\begin{array}{l}\text { Limit state design, } \\
\text { design of steel } \\
\text { members, } \\
\text { connections, } \\
\text { diaphragms, etc. }\end{array}$ \\
\hline $\begin{array}{l}\text { Reinforced concrete } \\
\text { design }\end{array}$ & $\begin{array}{l}\text { Structural concepts } \\
\& \text { Strength of } \\
\text { materials }\end{array}$ & $\begin{array}{l}\text { Limit state design, } \\
\text { reinforced concrete } \\
\text { design of flexural } \\
\text { and compression } \\
\text { members, etc. }\end{array}$ \\
\hline
\end{tabular}

\subsection{Data acquisition}

In order to assess the prerequisite skills outlined in Table 1, this longitudinal study involves repeated assessment of problem-solving skills while following student cohorts throughout the course of a 4-year structural engineering program. In this preliminary report of findings obtained for the first year, a total of 96 students from four distinct courses (see Table 2; Strength of materials, Structural concepts, Structural analysis and Steel Design) completed quizzes during the second week of the semester. Students were notified one week in advance on the topics covered in the quiz to begin reviewing and practising the prerequisite skills. A total of approximately 30 to 40 minutes was allowed for students to complete the quiz, depending on the course. Students were able to use a list of formulas to solve problems featured in each quiz.
The prerequisite skills in each of the four courses that are assessed in this study are shown in Table 2. Students are awarded a mark on the basis of the quiz results, either (i) Incorrect, (ii) Partially correct (for some problem only), or (iii) Correct. This method eases interpretation of interdependent skill sets, which is described in further details in the following section.

Table 2: Skill assessment

\begin{tabular}{|l|l|}
\hline Course & Prerequisite skills \\
\hline Strength of materials & $\begin{array}{l}\text { Centre of gravity, moment of inertia, shear } \\
\text { and bending moment diagrams. }\end{array}$ \\
\hline Structural analysis & $\begin{array}{l}\text { Normal stress, stress concentration, shear and } \\
\text { bending moment diagrams, shear and } \\
\text { bending stress of beams,. }\end{array}$ \\
\hline $\begin{array}{l}\text { Analysis of statically } \\
\text { indeterminate } \\
\text { structures }\end{array}$ & $\begin{array}{l}\text { Shear and bending moment diagrams, beam } \\
\text { deformation. }\end{array}$ \\
\hline Steel design & $\begin{array}{l}\text { Normal stress, stress concentration, shear and } \\
\text { bending moment diagrams, shear and } \\
\text { bending stress of beams, beam deformation. }\end{array}$ \\
\hline
\end{tabular}

\section{ASSOCIATION RULE MINING}

To discover the prerequisite structure of skills across each course, we applied an association rule mining technique to students' item responses. The prerequisite relationship between two skills represented as an association rule $(X \rightarrow Y)$ is measurable in terms of both its support and confidence. Support determines how often a rule is applicable to all item responses featured in the data set. Confidence determines how frequently item responses in $Y$ appear in item responses that contain $X$. Lift consists of the ratio between the confidence of a rule and the support of its consequent [3]. The gain metric captures instead the difference between both the confidence in the rule and the support of its consequent. Conviction is a measure similar to lift, but instead focuses rule direction by capturing the probability of both antecedent and consequent [3]. The formulas of these metrics are

Support, $s(X \rightarrow Y)=\sigma(X \cup Y) / N$

Confidence, $c(X \rightarrow Y)=\sigma(X \cup Y) / \sigma(X)$

Lift, $l(X \rightarrow Y)=c(X \rightarrow Y) / \sigma(Y)$

Conviction, $c o(X \rightarrow Y)=1-\sigma(Y) / 1-c(X \rightarrow Y)$

As an example, let's examine the following rule $\{$ Centre of gravity: Correct $\} \rightarrow\{$ Moment of Intertia_Partially Correct\}. Given that the data set contains 13 item responses where \{Centre of gravity:_Correct, Moment of inertia:_Partially Correct $\}$ and the total number of item responses is 36 , the rule's support is $13 / 36=0.36$. The rule's confidence is calculated by dividing the support count for \{Centre of gravity:_Correct, Moment of inertia:_Partially Correct $\}$ by the support count of $\{$ Centre of gravity:_Correct\}. Since there are 15 item responses where the Centre of gravity value was found to be correct, the confidence for this rule is $13 / 15=0.87$. The lift value 
of the rule is equal to the confidence divided by the support of $\{$ Moment of intertia:_Partially Correct $\}$, which is

$0.87 /(20 / 36)=1.57$. The conviction of the rule is thus $(1-(20 / 36)) /(1-0.87)=3.42$.

As such, the support of a rule is suggestive that students who have first mastered a less complicated skill, are then most likely to acquire a more complex skill. Confidence is an indicator of the reliability of the inference made by the rule. The higher the confidence, the more likely it is for a more complex skill to be mastered, once a less complicated skill has first been acquired by the learner. In the case of both lift and confidence, values far from 1 indicate an interesting relationship, with the highest possible value approaching infinity. It is noteworthy to mention that the co-occurrence of skill acquisition does not imply a causal relationship, which requires further knowledge about how these skills are practised, refined, and retained over time.

\subsection{FP-Growth Algorithm}

A minimum support threshold value of 0.2 is used to generate a set of frequent item responses. The RapidMiner standard implementation of the FP-Growth algorithm was used to create a compressed representation of the item responses. Each support count for item responses that overlap is mapped onto a path in the FP-tree, allowing for increased computational efficiency by extracting frequent item responses directly from the structure in memory and avoiding multiple passes over the data set. At each recursive step, a conditional FP-tree is evaluated by updating the support count along the path and removing infrequent item responses.

\subsection{Evaluation of Association Patterns}

As the size of item responses and the corresponding skills increases, it is important to establish subjective and objective criteria for evaluating the quality of association patterns. First, a minimum confidence threshold value of 0.8 is used to extract the most reliable rules from the frequent item responses found in the previous step. Second, the rules generated in relation to the skill \{Shear and bending diagrams $\mathrm{V}, \mathrm{M}$ \} were deemed interesting due to the fact that this particular skill is utilized in solving problems shown across all 3 cohorts of engineering students. The prerequisite structure of skills surrounding this commonly used skill component provides useful knowledge regarding skill development that can lead to curricular decisions.

\section{RESULTS}

We now discuss the findings obtained from the first year of the longitudinal study towards inferring the prerequisite structure of skills on the basis of associations in item responses. The data is labelled as a polynomial variable, where each skill is associated to a correct, partially correct, and incorrect response, collected from students enrolled in 4 distinct courses throughout multiple cohorts. The inferred preconditions may include multiple antecedents and consequents in each rule, as shown in Table 3 for the Diagrams V, M item. This item represents the shear and bending diagrams obtain from a statically determinate beam having concentrated and uniform loads only. For shear and bending stress calculations, the shear (V) and bending $(\mathrm{M})$ diagrams were given beforehand in order to make sure that stress calculation errors are not related to wrong answers from the $\mathrm{V}$ and $\mathrm{M}$ diagrams.

As an example, it can be seen from the association rules in Table 3 that the ability to complete the shear and bending diagrams is contingent on the shear and bending stress calculations for beams in the context of the structural analysis course. A total of 13 out of 27 item responses were captured using the relevant association rule (i.e., Shear and bending stresses in beams: Incorrect $\rightarrow$ Diagrams V, M : Partial), which corresponds to a support of 0.48 . The confidence of the rule, which takes into account the base occurrence rate of incorrect calculations of shear and bending stress on the beams (i.e., 16 out of 27 ), is 0.81 . The lift metric confirm that the two occurrences are dependent on one another given the observed support to that expected if both were independent (i.e., lift $=1.21$, which is greater than 1). Finally, the conviction value of 1.78 suggests that the rule would be incorrect $78 \%$ more often if the association was arbitrary. It is also noteworthy to indicate that the ability to complete the diagram is most often conceived as a prerequisite skill to more complicated skills throughout each course.

\section{CONCLUSION AND FUTURE WORK}

The objective in this study was to develop a set of diagnostic assessment tools that specifically target structural engineering knowledge and skills, and how these skills build upon one another throughout specific courses. Preliminary results were presented based on a limited amount of data since this is the first year of a three-year research study. In doing so, the study addressed the question of what skills are taught to be necessary for students to acquire prior to mastering more complex skills. The underlying assumption is that the proposed association rule mining method enables researchers to empirically validate a learning progression for skill acquisition in civil engineering. The prerequisite structure of skills in this domain can be inferred on the basis of performance on assessments, where skills that are dependent upon one another as most often found to co-occur in terms of both correct and incorrect responses to each item.

One of the most important limitations of the proposed method is that it does not capture several factors that pertain to skill acquisition, including the amount of prior exposure in courses, the recall of particular skills over time 
from long-term memory, the ability to transfer a particular skill to solving similar types of problems but with different features, the inherent level of difficulty of problem-solving items, as well as the fact that students may have acquired a skill, but nonetheless might have miscalculated or misjudged a specific step. Further research is necessary in representing item responses as well as capturing relevant factors through alternative modelling techniques that complement the association rule mining outlined in this paper.

The proposed method has implications for contemporary assessment practices established by the Canadian Engineering Accreditation Board. We argue that there is a need to establish a learning progression that is informed by empirical data regarding what skills should be acquired by engineering students as well as when should this occur throughout the entire curriculum. Furthermore, there is a need for better research infrastructure that allows engineering instructors to administer such assessments through the web in an effort to collect and analyze data at a larger scale, which is necessary to make generalizable claims regarding the prerequisite skill structure in civil engineering education.

\section{Acknowledgements}

The authors would like to thank Serge Desjardins, adjunct professor at the Université de Moncton civil engineering program, for his contribution to this work.

\section{References}

[1] C. Smith, M. Wiser, C.W. Anderson, \& J. Krajcik, "Implications for children's learning of assessment: A proposed learning progression for matter and the atomic molecular theory", Measurement, vol. 14, no. 1\&2, pp. 1-98, 2006.

[2] R. G. Duncan, C. E. Hmelo-Silver, "Learning progressions: Aligning curriculum, instruction, and assessment", Journal of Research in Science Teaching, vol. 46, no. 6, pp. 606-609, 2009.

[3] S. Brin, R. Motwani, J. D. Ullman, S. Tsur, "Dynamic item set counting and implication rules for market basket data" in SIGMOD, Acm-sigmod international conference on management of data, New York, NY, USA, 1997.

Table 3: Association rule mining of item responses for Diagrams V, M

\begin{tabular}{|c|c|c|c|c|c|}
\hline Premises & Conclusion & Support & Confidence & Lift & Conviction \\
\hline \multicolumn{6}{|c|}{ Strength of materials } \\
\hline $\begin{array}{l}\text { Diagrams V, M: Partial, Centre of } \\
\text { gravity: Correct }\end{array}$ & Moment of inertia: Partial & 0.28 & 1.00 & 1.80 & $\infty$ \\
\hline \multicolumn{6}{|c|}{ Structural analysis } \\
\hline $\begin{array}{l}\text { Shear and bending stresses in beams: } \\
\text { Incorrect }\end{array}$ & Diagrams V, M: Partial & 0.48 & 0.81 & 1.21 & 1.78 \\
\hline $\begin{array}{l}\text { Diagrams V, M: Partial, Shear and } \\
\text { bending stresses in beams: Incorrect }\end{array}$ & Normal stress: Incorrect & 0.41 & 0.85 & 0.91 & 0.48 \\
\hline Diagrams V, M: Partial & Normal stress: Incorrect & 0.59 & 0.89 & 0.96 & 0.67 \\
\hline Diagrams V, M: Correct & Normal stress: Incorrect & 0.30 & 1.00 & 1.08 & $\infty$ \\
\hline \multicolumn{6}{|c|}{ Steel design } \\
\hline $\begin{array}{l}\text { Deflection of beams: Incorrect, } \\
\text { Diagrams V, M: Correct }\end{array}$ & Normal stress: Incorrect & 0.61 & 0.91 & 1.04 & 1.36 \\
\hline Diagrams V, M: Correct & $\begin{array}{l}\text { Deflection of beams: Incorrect, } \\
\text { Normal stress: Incorrect }\end{array}$ & 0.61 & 0.91 & 1.04 & 1.36 \\
\hline Diagrams V, M: Correct & Normal stress: Incorrect & 0.61 & 0.91 & 1.04 & 1.36 \\
\hline $\begin{array}{l}\text { Deflection of beams: Incorrect, } \\
\text { Diagrams V, M: Correct, } \\
\text { Shear and bending stresses in beams: } \\
\text { Partial }\end{array}$ & Normal stress: Incorrect & 0.26 & 0.80 & 0.92 & 0.65 \\
\hline $\begin{array}{l}\text { Diagrams V, M: Correct, } \\
\text { Shear and bending stresses in beams: } \\
\text { Partial }\end{array}$ & $\begin{array}{l}\text { Deflection of beams: Incorrect, } \\
\text { Normal stress: Incorrect }\end{array}$ & 0.26 & 0.80 & 0.92 & 0.65 \\
\hline $\begin{array}{l}\text { Diagrams V, M: Correct, Shear and } \\
\text { bending stresses in beams: Partial }\end{array}$ & Normal stress: Incorrect & 0.26 & 0.80 & 0.92 & 0.65 \\
\hline
\end{tabular}

